\title{
Educação como mecanismo de superação das relações de opressão atravessadas pela fragilidade do Ego
}

\author{
Education as a mechanism of overcoming the relations of \\ oppression crossed by the weakness of the Ego
}

\author{
Alexandre Patrício de Almeida \\ Pontifícia Universidade Católica de São Paulo (PUCSP) \\ alexandrepatriciodealmeida@yahoo.com.br
}

Mateus Vitor dos Santos Universidade Paulista (UNIP) mateusvitor.9511@gmail.com

\begin{abstract}
Resumo: Diante da análise teórica e histórica sobre as relações de opressão e os mecanismos de defesa do Ego, com embasamento nas obras de Paulo Freire e Freud, pode-se afirmar que há uma significativa relação entre a fragilização do Ego, a consciência hospedeira e a manutenção de ideologias como mecanismo fundamental para tal processo de fragilização. Com a consolidação das cadeias de opressão que se fazem diante das realidades sociais, mantidas como imutáveis e afetadas pelas dificuldades apresentadas como intransponíveis, a educação é uma alternativa de transformação e criadora de possibilidades reais para todas as camadas sociais. Nesse sentido, o artigo discorre sobre a compreensão da necessidade do acesso à educação, bem como alguns dos fatores que permeiam a ausência desta.
\end{abstract}

Palavras chaves: Educação. Freud. Paulo Freire. Opressão. Psicanálise.

\begin{abstract}
In view of the theoretical and historical analysis of the relations of oppression and the defense mechanisms of the Ego, based on the works of Paulo Freire and Freud, it can be said that there is a significant relationship between the fragility of the Ego, the host consciousness and the maintenance ideologies as a fundamental mechanism for such a weakening process. With the consolidation of the chains of oppression that take place in the face of social realities, maintained as immutable and affected by the difficulties presented as insurmountable, education is an alternative for transformation and the creation of real possibilities for all social strata. In this sense, the article discusses the understanding of the need for access to education, as well as some of the factors that permeate its absence.
\end{abstract}

Keywords: Education. Freud. Paulo Freire. Oppression. Psychoanalysis. 


\section{Mecanismos psicológicos na história da relação opressor/oprimido}

Para se explorar o conhecimento psicológico nos mecanismos sociais, percorrer o caminho traçado pela historicidade dos fatos é uma via essencial. Na crítica ao que já foi vivido, existe a possibilidade de transformação, entretanto, em sua negação, há, ainda, a possibilidade de repetição. Lembremos, por exemplo, das palavras gravadas na entrada do museu de Auschwitz, do escritor e filósofo George Santayana: "Those who do not remeber the past are condemned to repeat it" ("Aqueles que não conseguem lembrar o passado estão condenados a repeti-lo", em tradução livre). Nesse sentido, pode-se dizer que a crítica ao vivido ocorre na pesquisa e investigação dos fatos e movimentos experienciados no mundo. O efeito das verdades que são apregoadas culturalmente e socialmente cria determinações, que são carregadas de ideologias, ideais de superioridade ou inferioridade e legitimam muitas opressões. Foi assim com o Nazismo; é assim em grande parte dos regimes ditatoriais.

A ideologia, no seu dia-a-dia, vai criando significados, sentidos, definições de determinadas realidades. Esses significados e sentidos têm sempre uma conotação de valor, positivo ou negativo. Por exemplo: a partir de aparências, nem sempre fundamentadas, começamos a dizer que homens, ou as mulheres, são mais trabalhadores, mais honestos (as), etc. Ou começamos a dizer que os brasileiros são mais bondosos, que os japoneses são mais trabalhadores, que os negros são mais festeiros, etc. Dizendo com outras palavras: vamos criando juízos de valor, discriminações, estereótipos, preconceitos. Vamos juntando, ligando qualidades, características valorativas a determinadas pessoas ou coisas. (GUARESCHI, 2007, p. 91).

O subsídio de muitas ações repressoras que tiveram efeitos históricos estava pautado em falsas verdades, sejam estas permeadas por fundamentalismos religiosos, por perspectivas únicas que desconsideravam novas possibilidades de vida ou outros fatores. A colonização, por exemplo, desconsidera o projeto de vida de um povo, por considerá-la inferior, colocando a cultura, hábitos e crenças do colonizador como essencial e única possível. No Brasil, o período colonial foi marcado por um desmonte dos hábitos e práticas sociais dos povos originários, sequenciado por imposições dos costumes portugueses. Podemos entender a cultura do oprimido em contrapartida a do opressor, principalmente ao que tange as suas bases ideológicas. Este é um dos aspectos do impacto da ação ideológica: sem a mínima autocrítica impõe-se como ordem (e padrão) aquilo que se considera como adequado - o que gera uma intolerância à diversidade, resultando na aniquilação das diferenças, como o que ocorreu com os povos indígenas. 
Mais recentemente, Hitler, entre a Primeira e a Segunda Guerra Mundial conseguiu admiradores e adeptos de seus ideais, após a derrota da Alemanha na Primeira Guerra. Este sentimento de humilhação e perda nutriu a instabilidade nacional e a baixa autoestima coletiva do povo alemão - constituindo um solo fértil para Hitler implantar os seus posicionamentos incisivos, nacionalistas, autoritários e extremistas. O quadro de vulnerabilidade da Alemanha pós-guerra serviu como uma grande oportunidade para Hitler disseminar tais posicionamentos e seguir com seus objetivos tão destrutivos para humanidade como um todo. Além disso, desde a publicação do livro "Minha luta" (Mein Kampf), em 1925, Hitler advertia sobre os perigos da mistura das raças e já considerava a raça ariana superior a qualquer outra. Durante o seu comando, a massa da população encontrava-se cada vez mais submetida ao poder totalitário do Fübrer, cuja figura se confundia com a da própria Alemanha, que passou a contar com um único partido, o Nacional-Socialista.

Neste ponto, podemos recorrer a algumas ideias do arsenal psicanalítico para compreendermos, de modo geral, os funcionamentos psíquicos presentes nas organizações totalitárias. Freud, em "Psicologia das massas e análise do Eu" (1921), volta-se para o fato de o Ego fragilizado ser um fator significativo para que os indivíduos tomem por ideal a figura de pessoas que estão em posições de "poder", afirmando que:

É evidente que o soldado toma por ideal seu superior, o líder do Exército, na verdade, enquanto se identifica com os seus iguais e deriva dessa comunidade do Eu as obrigações de auxílio mútuo e partilha de bens, que a camaradagem traz consigo. Mas ele se torna ridículo quando quer se identificar com o general. (FREUD, 1921/2011, p. 99)

Vale ressaltar, no entanto, que na assertiva acima o "tomar por ideal" não significa agir ao mesmo modo, mas realizar-se na ação do outro, como um ideal externo que é integrado ao próprio indivíduo, apropriando assim da fala e das ações do outro, sem que o próprio sujeito necessite agir do mesmo modo. Como menciona Herf (1993), entre 1929 e 1933, ano em que Hitler assumiu o comando,

[...] a depressão revelou situar-se além da capacidade de manejo do sistema político alemão [...] cresceram o desemprego e os extremistas políticos, retraíram-se os partidos de centro, a baixa classe média foi atraída pelos nazistas, os comunistas continuaram a atacar os socialdemocratas, taxando-os de "social-fascistas", os intelectuais direitistas sonhavam com esmagar a república e, por último, os conservadores voltaram-se para Hitler a fim de administrar ao regime os últimos sacramentos. (HERF, 1993, p. 33) 
Posto isso, o ideal de liberdade e crescimento do Estado Alemão foi comprado e identificado pela maioria da população, que estava psiquicamente debilitada após as crises advindas da Primeira Guerra. Dentre as instituições do partido nazista, o sistema jurídico passou a exercer um maior peso sobre as estruturas sociais, no sentido de que os interesses do Estado e da segurança do povo alemão estavam resguardados por esse sistema totalitário, em descompasso com os valores da justiça e a proteção dos menos favorecidos. O regime de Hitler, portanto, representava a possibilidade de ascensão do povo alemão (ariano), por isso foi apoiado tão facilmente. A fragilidade do Ego destes indivíduos, portanto, desembocou em tal processo que deixou marcas permanentes nas tramas da história.

Paralelo a isso, Freud (1921/2011) nos dirá que “cada indivíduo é um componente de muitos grupos, tem múltiplos laços por identificação, e construiu seu ideal do Eu segundo os mais diversos modelos” (p. 92). Assim, cada indivíduo participa do núcleo de muitos grupos, deste que estes estejam identificados, majoritariamente, com a sua raça, classe, fé, ideais, nacionalidade etc.

Segundo a perspectiva psicanalítica, esta visão tem sentido se apoiada em uma consideração de Freud sobre o quanto é difícil para o homem viver em sociedade; consideração esta que atravessa toda sua obra, extraída de sua experiência clínica. Nestes termos, Freud insiste em apontar como é difícil conviver com o outro, acrescentando ainda o quanto é penoso se reconhecer a diferença, apesar do outro ser imprescindível para que o próprio sujeito venha a se constituir como tal. (HERZOG, 2019, p. 274)

Ao partirmos para os aspectos psíquicos, vistos sob a luz da teoria psicanalítica, notamos que a relação entre a perda do "Eu individual", outrora fragilizado, que se restabelece ancorado em um "Eu coletivo", autoritário, que se integra ao "Eu individual" é, por último, um Eu assumido para si. Explicamos melhor: o indivíduo fragilizado psiquicamente assume para si próprio as identificações construídas com base no referencial de um Eu coletivo, delineado pelas marcas do autoritarismo. Esse mecanismo presente em estruturas totalitárias, oferece uma espécie de preenchimento simbólico para as lacunas deixadas por um Eu fragilizado. Tal processo explicaria, basicamente, o sucesso da ascensão de regimes fascistas, por exemplo - o que viemos discutindo até aqui.

Seguindo esta via, Theodor Adorno, em sua obra "Ensaios sobre psicologia social e psicanálise", afirma que: 
A formação do imaginário de uma figura paterna onipotente e não controlada, transcendendo em muito o pai individual e, assim, apta a ser engrandecida em um "eu do grupo", é a única via de promulgar a "atitude passivamente masoquista a quem alguém deverá se render". (ADORNO, 2007, p. 164)

A ancoragem em um "Eu maior", por parte do "Eu fragilizado" que se apega a tal ideal (figura paterna onipotente) na tentativa de obter segurança para si, mesmo que inconscientemente, nasce num ciclo que se retroalimenta em concordância com o fascismo e opressão. A identificação da massa com o líder e com seus pares alienados às determinações do mesmo, é também exposta por Freud na assertiva abaixo:

\begin{abstract}
Notemos que nessas duas massas artificiais [igreja e exército] cada indivíduo se acha ligado libidinalmente ao líder (Cristo, general), por um lado, e aos outros indivíduos da massa, por outro lado. (...) Se ocorre, para cada indivíduo, uma tão pródiga ligação afetiva em duas direções, não será difícil derivar dessa situação aquilo que se constatou, ou seja, a mudança e limitação de sua personalidade. (FREUD, 1921/2011, p. 49, colchetes nossos)
\end{abstract}

Na ligação narcísica, o indivíduo vai buscar nos objetos o idêntico ou o semelhante. Vai amar aquilo que gostaria de ser; ou que foi, ou parte de si. Esses objetos, decorrentes de escolhas narcísicas, são os mais intensos e difíceis de serem desvinculados; como irá ocorrer na melancolia, onde a perda do objeto amado representa uma mutilação para o Eu do sujeito. Paradoxalmente, o desenvolvimento do Eu exige, de fato, um afastamento do narcisismo primário ${ }^{1}$. Ao decorrer de sua trajetória, o indivíduo busca esta sensação de plenitude inicial, uma espécie de "ideal de Eu", e obtém a satisfação oriunda da realização deste ideal (seja de modo direto - por ele mesmo -, ou indireto - através de identificações com o outro). Por um lado, se o Eu se torna empobrecido em decorrência dos investimentos nesses objetos externos, por outro, o Eu também se enriquece ao ser realizado por seu ideal. No caso da Alemanha nazista, Adorno (2007) comenta que ao escolher o Führer como seu ideal, o indivíduo, embora ame a si mesmo (resquícios do narcisismo primário), livra-se das frustrações advindas das lacunas deixadas em seu Eu fragilizado.

Aqui, consideramos importante salientar a diferenciação dos conceitos "Eu ideal" e "ideal do Eu", elaborados por Freud em 1914 e expandidos por diversos autores. O Eu ideal compreende um ideal narcísico de onipotência, formado com base no modelo de

\footnotetext{
${ }^{1}$ Período inicial da vida, após o nascimento, onde representamos tudo para os nossos pais. Nas palavras de
} Freud (1914): His majesty, the baby (Vossa majestade, o bebê). 
narcisismo primário infantil. O Eu ideal é, também, um conjunto de um emaranhado de identificações do indivíduo com personagens admiráveis de sua história, com traços marcantes de autoridade e força. Já o ideal do Eu é uma expressão utilizada por Freud, que representa um modelo no qual o sujeito busca conformar-se. É baseado, por sua vez, nas identificações com os pais, com seus substitutos e com os ideais da coletividade. Ela explica a relação de submissão ao líder ou de dependência amorosa - um Eu fragilizado será, nesse sentido, uma estrutura vulnerável aos "atrativos" oferecidos por um ideal do Eu.

Logo, embora o líder deva surgir como uma figura dotada de super poderes, ele precisa representar, concomitantemente, uma pessoa comum, como ocorreu com Hitler, para propiciar a identificação por parte de todos os indivíduos que constituem a massa. Isso faz com que os seguidores satisfaçam seu duplo desejo: de se submeterem ao líder autoritário paterno e de almejarem ser, ao mesmo tempo, a própria figura de autoridade, representada pelo grande homem comum. Essa configuração social e psíquica já nos é suficiente para pensarmos as relações de opressão existentes no contexto contemporâneo questões que pretendemos explorar nos próximos itens do artigo.

\section{A legitimação das relações de opressão no contexto neoliberal}

Aceitar o fascismo por si só seria inconcebível sem que se explorasse um contexto anterior que o constituiu a partir de realidades individuais que, somadas, constroem o coletivo e pela troca coletiva, inferem no âmbito individual. A ancoragem em uma figura imageticamente una e poderosa, pode ser entendida como um mecanismo de defesa do Ego para sua própria satisfação.

Consequentemente, um dos dispositivos básicos da propaganda fascista personalizada, é o conceito do "pequeno grande homem", uma pessoa que sugere tanto onipotência quanto a ideia de que é apenas mais um do povo, um norte-americano pleno e viril, não maculado por riqueza material ou espiritual. A ambivalência psicológica auxilia a operar o milagre social. A imagem do líder satisfaz o duplo desejo do seguidor em se submeter à autoridade e ser ele mesmo a autoridade. (ADORNO, 2007, p. 172)

Sendo assim, cada indivíduo se entende como "uma" autoridade e se reconhece na identificação com uma figura que é construída e vendida como possibilidade de autorrealização, pois o outro está para si, assim como si, está para o outro. De maneira que ambos se dependem, de forma análoga, para que possam se sustentar. 
$\mathrm{Na}$ contemporaneidade, para se entender algumas das configurações sociais, é indispensável compreender o neoliberalismo, que permeia a sociedade. A lógica neoliberal carrega em si o favorecimento da lógica de mercado, a qual segue em concordância com o lucro sobreposto ao interesse humano. O que é ignorado, então, é que mesmo que se possua uma produção a custo zero, buscando o lucro integral do capitalista (aquele que detém o capital e expropria a força de trabalho), se a classe operária não possuir poder de consumo, não haverá possibilidade de lucro, que é obtido pelo consumo da massa de maneira expressiva.

A liberdade do comércio não pode estar acima da liberdade do ser humano. A liberdade do comércio sem limite é licenciosidade do lucro. Vira privilégio de uns poucos que, em condições favoráveis, robustece seu poder contra os direitos de muitos, inclusive o direito de sobreviver. (FREIRE, 2019, p. 126)

Numa configuração social, onde se é alguém apenas quando se tem algo, "ter" é supervalorizado em detrimento do "ser", portanto, não se reconhece o ser coexistindo socialmente sem que o mesmo tenha poder econômico para consumir. Implicando, assim, nos processos identitários e, por conseguinte, na estruturação do Eu. Maria Rita Kehl, em seu livro "O tempo e o cão" aponta algumas críticas sobre o excesso de estímulos presentes nos dias de hoje, relacionando-os às questões do consumo e, também, da sociedade do espetáculo - o que acaba por afastar o sujeito do contato com ele próprio e, consecutivamente, da descoberta de si mesmo. Citamos a autora:

[...] ao contrário da diferença de posições que institui um intervalo entre a massa e o líder, a torrente ininterrupta de imagens não inclui a falta (...) a qual convoca o sujeito ao trabalho psíquico de representação até inserir-se, como personagem de sua ficção particular, entre as figuras fictícias do espetáculo. As imagens imperativas e ininterruptas da indústria do espetáculo dispensam o trabalho subjetivo que articula a identificação à perda do objeto, uma vez que reduzem a zero o tempo que separa o momento da perda daquele da recuperação do objeto através da identificação imaginária. (KEHL, 2015, p. 290)

O ideário neoliberal introduz na cultura, referenciais de superioridade, de acordo com o consumo, não pelo valor de uso dos objetos apenas, mas, também, pelo valor social aplicado ao objeto. A fragilidade e liquidez do consumo, além de insaciáveis, são, ao mesmo tempo, facilmente utilizadas como fator de enfraquecimento do Ego de quem não consome, não pertence e, deste modo, não existe.

De modo equivalente aos ideais presentes nos regimes totalitários que apresentamos no início de nosso trabalho, a sociedade do consumo impõe ao sujeito um 
modelo a ser seguido dentro de uma exigência que, muitas vezes, acaba sendo inatingível. Dentro da ótica freudiana, o poder de compra estaria atrelado ao "ideal do Eu", pois seria capaz de preencher as rupturas deixadas por um Eu frágil. O comprar situa o sujeito dentro da massa - o que Adorno (2007) denominou de Eu de grupo. Vamos de encontro a um ciclo predatório que afasta o sujeito de sua verdadeira identidade, ao mesmo tempo em que o lança às mazelas de um vazio existencial ilusório oriundo deste raso preenchimento.

\section{Consciência hospedeira e fragilidade do Ego}

Em sua obra "Psicologia das massas e a análise do eu" (1921), Freud considera a figura do líder das massas como inspirador de temor e referencial de força. O psicanalista afirma que:

O caráter inquietante e compulsivo da formação da massa, evidenciado em seus fenômenos de sugestão, pode então ser remontado, com justiça, à sua origem a partir da horda primeva. O líder da massa continua a ser $\mathrm{o}$ temido pai primordial, a massa quer ainda ser dominada com força irrestrita, tem ânsia extrema de autoridade, ou, nas palavras de Le Bon, sede de submissão. O pai primevo é o ideal da massa, que domina o Eu no lugar do ideal do Eu. (FREUD, 1921/2011, p. 91)

Sede de submissão esta, outrora construída e articulada, de modo que se aceite tudo de modo irrestrito, dando abertura para o fascismo (e outros regimes totalitários) e a dependência quase integral do outro. Entre o fatalismo e a precarização de condições para se e viver e pensar, nos deparamos com as questões que abarcam a fragilidade do Ego que impulsiona tal "sede de submissão".

Grandes períodos de recesso podem gerar fenômenos depreciativos para a humanidade, pois colocam pessoas em situações de risco e de submissão e, ainda assim, podem acender o consentimento dos que estão na posição de oprimidos, justamente por desejarem estar no lugar do opressor e não romper com o lugar de opressão, extinguindo tal posição. Porém, quando então o oprimido "conforma-se" com a sua posição, não acreditando na probabilidade de mudança, abre-se a possibilidade de que ele se identifique com o opressor por nutrir-se do seu poder autoritário. Nesse sentido, chegamos a matriz ideológica do funcionamento de um dos principais mecanismo utilizados para garantir a manutenção de ideais expropriadores de poder, assim como também, a alienação social, marginalizando parte das maiorias demográficas - detentoras do poder real sobre a sociedade, mas, que, no entanto, desconhecem esse potencial em sua magnitude, pois ao 
serem atingidas por esses potentes referenciais, tomam essas figuras como ideias do Eu, passíveis de serem incorporados a sua real identidade.

De acordo com Freud (1926), um Ego fragilizado, estruturado como mecanismo de defesa, pode vir a gerar a identificação do sujeito com um Superego tirânico. O Superego é a estrutura psíquica responsável por controlar os impulsos inconscientes (Id) - uma espécie de ordem e moral resultante do Complexo de Édipo. Posto isso, pode-se afirmar que há casos em que a popularidade de líderes tirânicos e extremistas tenha sido perpetuada pela fragilidade do Ego dos sujeitos oprimidos, fragilidade esta que é mantida pelas ideologias (falsas verdades descoladas da realidade material). Esse movimento acaba por gerar despersonalização, alienação e objetificação.

Mas essa identificação dos oprimidos com a classe que os domina e explora é apenas parte de um contexto maior. Aqueles que podem estar afetivamente ligados a esta; apesar da hostilidade, enxergam nos senhores o seu ideal. Se não existissem tais relações fundamentalmente satisfatórias, seria incompreensível que certas culturas se conservassem por tanto tempo, não obstante a justificada hostilidade de grandes massas. (FREUD, 1926/2014, p. 244)

Com a reprodução irrestrita de modelos sociais, pode-se afirmar que a realidade estabelecida é questionável, porém perpetuada pelas demandas previamente estimuladas. O oprimido, não reconhecendo perspectivas satisfatórias em seu eu, busca a sua satisfação na satisfação do opressor, da figura de poder, identificando seu ideal de forma alheia a si. Trata-se de um processo que pode ser identificável na chamada "consciência hospedeira", quando então, o oprimido deseja a manutenção desta posição, para que busque ocupá-la e não a extinguir.

A consciência hospedeira garante a manutenção do status quo, perpetuando a lógica de dominação, onde o poder está associado ao capital, ao consumo e à sustentação dos mesmos padrões entendidos como superiores, sem os mínimos questionamentos. A ideologia deseja insistentemente que os oprimidos se curvem aos interesses dos opressores, reafirmando a impossibilidade de transformar a própria realidade social, de maneira macro. É possível observar tais pontos na assertiva de Paulo Freire:

A ideologia fatalista, imobilizante, que anima o discurso neoliberal anda solta pelo mundo. Com ares de pós-modernidade, insiste em convencernos de que nada podemos contra a realidade social que, de histórica e cultural, passa a ser ou virar "quase natural". Frases como "a realidade é assim mesmo, o que podemos fazer?" ou "o desemprego no mundo é uma fatalidade do fim do século" expressam bem o fatalismo desta ideologia e sua indiscutível vontade imobilizadora. (FREIRE, 2019, p. 21) 
O autor nos aponta para um pensamento acerca da dimensão identificatória, ou seja, ao passo que existe uma identificação intrínseca do sujeito ao opressor há, também, uma identificação em massa que gera comodidade ancorada por uma posição de passividade que impera nos contextos de opressão social e cultural. O conformismo passa ser visto, então, como a única saída perante a imposição que "vem de cima" - o que o autor denominou de "vontade imobilizadora".

A produção de fragilidades acontece de forma intrínseca na impossibilidade que é apresentada como realidade social. Assim como a responsabilização do oprimido, por sua condição, desconsiderando seu contexto socioeconômico, cultural e histórico. "É importante ter claro que faz parte do poder ideológico dominante a inculcação nos dominados da responsabilidade por sua situação” (FREIRE, 2019, p. 80).

Ao mencionar a responsabilização pela própria situação, trata-se de salientar a realidade material que já estava dada ideologicamente, sem desconsiderar a dialética que constitui a existência, criando possibilidades e o reconhecimento do homem como produto e produtor de sua vida - o que não permite legitimar a irresponsabilidade sobre as escolhas individuais, mas, não fecha os olhos para os fatores que o cercam. Sendo que, a expropriação de poder, não possibilita a autonomia, que seria uma ferramenta para ressignificação e transformação das relações de dominação, de modo a questionar ideologias introjetadas pela via da consciência hospedeira. Em contrapartida, Paulo Freire elucida:

A alfabetização, por exemplo, numa área de miséria, só ganha sentido na dimensão humana se, com ela, se realiza uma espécie de psicanálise histórico-político-social, de que vá resultando a extrojeção da culpa indevida. A isto corresponde a "expulsão" do opressor de dentro do oprimido, enquanto sombra invasora. Sombra que, expulsa pelo oprimido, precisa ser substituída por sua autonomia e sua responsabilidade. (FREIRE, 2019, p. 81)

Porém, a situação torna-se ainda mais complexa, quando interligamos essas noções freirianas às provocações de Freud. Citamos o autor, à guisa de ampliarmos a nossa discussão:

A satisfação narcísica advinda do ideal cultural é também uma das forças que atuam eficazmente contra a hostilidade à cultura interior do grupo cultural. Não apenas as classes privilegiadas que desfrutam os benefícios desta cultura, mas também os oprimidos podem partilhar essa satisfação, pois o direito de desprezar aqueles de fora os compensa pelos danos que sofrem no seu próprio grupo. (FREUD, 1926/2014, p. 244) 
Com a análise das relações de opressão que estão correlacionadas à perpetuação de ideologias dominantes que são mantidas pela consciência hospedeira, que pode ser lida através do aparelhamento psíquico apresentado por Freud ${ }^{2}$ e pelos mecanismos de identificação e defesa do Ego, podemos entender parte do funcionamento de alguns fenômenos sociais e históricos. Ao observarmos um determinado grupo social, compreendemos que algo ali, como uma espécie de ideal comum, os mantém unidos, mas, como nos aponta Freud, algo a mais fortalece o elo entre os seus membros: "partilhar a satisfação em poder desprezar aqueles que ficam de fora". Consequentemente, dentro da dinâmica contemporânea, ao fazer o consumo de determinado bem material, isso torna o indivíduo mais próximo da estrutura que antes o excluía, o que não impede, de maneira absoluta, que ele próprio passe a praticar a exclusão com o seu semelhante. Logo, esse movimento investigativo nos auxilia a questionar o status quo e a construir conhecimentos que possam facilitar a consolidação da subjetividade, do fortalecimento do Ego e, assim, evitar que histórias de violência, intolerância e fascismo se repitam.

\section{Criação de possibilidades transformadoras pela educação}

Diante das discussões realizadas, percebemos que um povo precisa acreditar em si; em sua capacidade produtiva (material, intelectual, cultural); ter sua subjetividade consolidada pela autoestima; e romper com as relações de exploração que são consumadas quando não se vê alternativa, que não a submissão. Citamos Freire:

Ao fazer-se opressora, a realidade implica na existência dos que oprimem e dos que são oprimidos. Estes, a quem cabe realmente lutar por sua libertação juntamente com os que com eles em verdade se solidarizam, precisam ganhar a consciência crítica da opressão, na práxis desta busca. (FREIRE, 1987, p. 24)

De acordo com a afirmação do autor, é possível aferirmos que é por meio do conhecimento; de um referencial solidário; do coletivo; do emancipatório; e do colaborativo, que seremos capazes de viabilizar o desenvolvimento de maneira sustentável. E, para isso, é necessário e imprescindível notar a potência existente em cada indivíduo que compõe a massa, não por suas limitações ou aquilo que se acredita que seja desqualificador, mas, sim por sua capacidade que pode ser trabalhada e desenvolvida pela esfera pedagógica. Se um Eu fragilizado se constrói, principalmente, com base nas identificações sociais, é justamente neste campo que uma ação educativa transformadora deve ocorrer. Enquanto

${ }^{2}$ Mais precisamente em seu texto “O Ego e o Id” publicado, originalmente em 1923. 
houver referências totalitárias de um suposto "ideal do Eu", teremos de conviver com a alienação que gera tantos prejuízos ao progresso cultural.

A educação talhada na pluralidade e diversidade, capaz de legitimar a consolidação dos processos identitários, atravessando as determinações ideológicas e as desconstruindo, é um ciclo que tende a possibilitar a olhar para as fragilidades do Ego, que são impostas dentro de um contexto retroalimentado. No fazer pedagógico mora a resistência à opressão - onde torna-se impossível sustentar a neutralidade. Como categoricamente afirmado por Freire:

Creio que nunca precisou o professor progressista estar tão advertido quanto hoje em face da esperteza com que a ideologia dominante insinua a neutralidade da educação. Desse ponto de vista, que é reacionário, o espaço pedagógico, neutro por excelência, é aquele em que se treinam alunos para práticas apolíticas, como se a maneira humana de estar no mundo fosse ou pudesse ser uma maneira neutra. (FREIRE, 2019, p. 96).

Neste sentido, convidamos o leitor deste trabalho a refletir a respeito da similaridade que há entre a neutralidade e a indiferença. Em nossa concepção, observamos que é na prática educadora que encontramos a emancipação, que só existe na criticidade acerca do que se apresenta, não apenas na reprodução deste ou daquele modelo, mas pela possibilidade de que se tenha um solo fértil o suficiente para pensar, construir saberes e valorizá-los. Pelo reconhecimento das culturas, reflexões do que se é em sua total realidade, possibilitamos, na medida do possível, o desdobramento do poder vir a ser - indispensável à libertação do sujeito.

Adentrar em contextos, atualizar-se, caminhar em conjunto com a realidade material que envolve a prática educacional, torna-nos capaz de acompanhar as mudanças e, em paralelo, mudar positivamente no sentido do progresso humano que se deseja.

Uma vez que nosso lugar no mundo está sempre mudando, precisamos aprender constantemente, para estarmos totalmente presentes no agora. Se não estamos completamente engajados no presente, ficamos presos no passado e a nossa capacidade de aprender é diminuída. (HOOKS, 2019, p. 201).

No entanto, revisitar o passado é uma tarefa indispensável para pensarmos acerca de nossa própria existência. A constância no movimento do mundo é sinônima de constância no movimento da educação, que segue construindo como processo interminável que se adapta e cria saídas para dominações e expropriações de poder, driblando a alienação imposta por regimes ditatoriais. $O$ conflito gera questionamentos e o questionamento gera conhecimento. 
Práticas autoritárias, promovidas e encorajadas por muitas instituições, minam a educação democrática da sala de aula. ao atacar a educação como prática da liberdade, o autoritarismo desumaniza e, por isso destrói a "magia" que está sempre presente quando os indivíduos são aprendizes ativos. (HOOKS, 2019, p. 201, grifos nossos).

O autor nos indica, portanto, que "aprendizes ativos" é um termo que pode ser direcionado a todos, dentro e fora do contexto acadêmico. A educação democrática atravessa paredes e papéis, pois ela acontece na prática coerente e cotidiana, na partilha e no diálogo, sem restringir o ouvir e o escutar, refletir e assimilar, criando legitimamente a apropriação de saberes. "Ao longo do processo de aprendizagem, a escola deve adotar intervenções que possibilitem o desenvolvimento intelectual, afetivo e social de seus alunos, atentando-se às semelhanças e respeitando as personalidades" (ALMEIDA, 2018, p. 35). Entretanto, por conta das dificuldades encontradas no percurso desta práxis, o ensino acaba se realizando de maneira fragmentada, sem propiciar a relação entre o conhecimento formal e a realidade do aluno, e o seu exercício torna-se algo desprovido de fundamento, um saber afastado do contexto real (ALMEIDA, 2018).

Diante dos assinalamentos acima, trazemos, como ponto basal deste trabalho, um recorte da compreensão de aspectos decorrentes da tríade: "educação, política e psiquismo". Áreas que estão correlacionadas, coexistindo na concepção da sociedade, de maneira indissociável. A tomada de consciência não acontece em si, mas no movimento coletivo em direção à práxis da liberdade. A educação, portanto, cria possibilidades de conhecimento. A política, por sua vez, garante a manutenção dos espaços de educação e cada sujeito em sua individualidade psíquica compõe o seu meio social. Um fazer pedagógico capaz de alçar voo e ultrapassar os limites da ortodoxia. Só assim, quem sabe, encontraremos uma esperança em meio ao obscurantismo do totalitarismo. Precisamos desse movimento (hoje, mais do que nunca!).

\section{Referências}

ALMEIDA, A. P. Psicanálise e educação escolar: contribuições de Melanie Klein. São Paulo: Zagodoni, 2018.

ADORNO, T. W. Ensaios sobre psicologia social e psicanálise. São Paulo: Editora Unesp, 2007.

FREIRE, P. Pedagogia do oprimido. 17. ed. Rio de Janeiro, Paz e Terra, 1987.

FREIRE, P. Pedagogia da autonomia. 58. ed. Rio de Janeiro: Paz e Terra, 2019. 
FREUD, S. (1914). Introdução ao narcisismo. In: Sigmund Freud. Introdução ao narcisismo: ensaios de metapsicologia e outros textos (1914-1916). Vol. 12. São Paulo: Companhia das Letras, 2010.

FREUD, S. (1921). Psicologia das massas e análise do eu. In: Sigmund Freud. Psicologia das massas e análise do eu e outros textos (1920-1923). Vol. 15. São Paulo: Companhia das Letras, 2011.

FREUD, S. (1926). O futuro de uma ilusão. In: Sigmund Freud. Inibição, sintoma e angústia, o futuro de uma ilusão e outros textos (1926-1929). Vol 17. São Paulo: Companhia das Letras, 2014.

GUARESCHI, P. A. Relações comunitárias, relações de dominação. In: CAMPOS, Regina Helena de Freitas. (Org.). Psicologia social comunitária: Da solidariedade à autonomia. 13. ed. Petrópolis: Vozes, 2007. pp. 81-99.

HERF, J. Modernismo reacionário: tecnologia, cultura e política em Weimar e no Terceiro Reich. Trad. Cláudio Frederico da S. Ramos. Campinas: Ensaio/Editora da Unicamp, 1993.

HERZOG, R. Do preconceito à intolerância: quando se rouba a humanidade do outro. Ágora (Rio J.), Rio de Janeiro, v. 22, n. 3, p. 273-279, dez. 2019.

HOOKS, B. Educação democrática. In: CÁSSIO, Fernando. et al (org.). Educação contra a barbárie: Por escolas democráticas e pela liberdade de ensinar. São Paulo: Boitempo, 2019. pp. 198207.

KEHL, M. R. O tempo e o cão: a atualidade das depressões. São Paulo: Boitempo, 2009.

Recebido em: 11 nov. 2019 / Aprovado em: 03 mar. 2020.

Cite como (ABNT NBR 6023:2018)

ALMEIDA, Alexandre Patrício de; SANTOS, Mateus Vitor dos. Educação como mecanismo de superação das relações de opressão atravessadas pela fragilidade do Ego. Dialogia, São Paulo, n. 34, p. 337-350, jan./abr. 2020. Disponível em: https://doi.org/10.5585/Dialogia.N34.16008. 